\author{
Adriaan Campo ${ }^{1}$ \\ Ultrasound Elasticity Imaging Laboratory, \\ Columbia University, \\ Columbia University Medical Campus, \\ 630 West 168th Street, \\ Physicians \& Surgeons 19-418, \\ New York, NY 10032; \\ Laboratory of Biomedical Physics, \\ Antwerp University, \\ Campus Groenenborger, \\ Groenenborgerlaan 171 G.U.339, \\ Antwerp 2020, Belgium \\ e-mail: adriaan.campo@ua.ac.be \\ Matthew D. McGarry \\ Thayer School of Engineering Dartmouth, \\ 14 Engineering Drive, \\ Hanover, NH 03755 \\ e-mail: matthew.d.mcgarry@dartmouth.edu

\section{Thomas Panis} \\ Radiology Department, \\ University Hospital of Brussels, \\ UZ Brussel, Campus Jette, Laarbeeklaan 101, \\ Brussels B-1090, Belgium \\ e-mail: Thomas.panis@gmail.com \\ Joris Dirckx \\ Laboratory of Biomedical Physics, \\ Antwerp University, \\ Campus Groenenborger, \\ Groenenborgerlaan 171 G.U.342, \\ Antwerp 2020, Belgium \\ e-mail: joris.dirckx@ua.ac.be

\section{Elisa Konofagou} \\ Ultrasound Elasticity Imaging Laboratory, \\ Columbia University, \\ Columbia University Medical Campus, \\ 630 West 168th Street, \\ Physicians \& Surgeons 19-418, \\ New York, NY 10032 \\ e-mail: ek2191@columbia.edu
}

\section{Effect of Local Neck Anatomy on Localized One-Dimensional Measurements of Arterial Stiffness: A Finite-Element Model Study}

Cardiovascular diseases (CVD) are the most prevalent cause of death in the Western World, and their prevalence is only expected to rise. Several screening modalities aim at detecting CVD at the early stages. A common target for early screening is common carotid artery (CCA) stiffness, as reflected in the pulse wave velocity $(P W V)$. For assessing the CCA stiffness using ultrasound (US), one-dimensional (1D) measurements along the CCA axis are typically used, ignoring possible boundary conditions of neck anatomy and the US probe itself. In this study, the effect of stresses and deformations induced by the US probe, and the effect of anatomy surrounding CCA on a simulated $1 D$ stiffness measurement $\left(P W V_{u s}\right)$ is compared with the ground truth stiffness $\left(P W V_{g t}\right)$ in 60 finiteelement models (FEM) derived from anatomical computed tomography (CT) scans of ten healthy male volunteers. Based on prior knowledge from the literature, and from results in this study, we conclude that it is safe to approximate arterial stiffness using $1 D$ measurements of compliance or pulse wave velocity, regardless of boundary conditions emerging from the anatomy or from the measurement procedure. [DOI: 10.1115/1.4042435]

\section{Introduction}

Cardiovascular diseases (CVD) are the most prevalent cause of death in the Western World, and their prevalence is only expected to rise [1]. CVD usually has a gradual onset, passing through several different stages before symptomatic stages are experienced. Research shows that when detected at the early stages, the onset of CVD can be slowed down or even prevented with appropriate medical guidance.

Ultrasound (US) imaging of the common carotid artery (CCA) wall is relatively inexpensive, widely available, time efficient, and readily applicable to asymptomatic populations. An important strength of ultrasonography is its ability to retrieve highly timeresolved measurements of vessel wall motion and deformation, allowing the arterial mechanical properties to be studied. This has been proven to be relevant to a wide range of arterial diseases, including atherosclerosis [2-4], aneurysms [5,6], hypertension $[7,8]$ and aging $[9,10]$. Several time-resolved US methods to study artery mechanical properties noninvasively are under development at present.

\footnotetext{
${ }^{1}$ Corresponding author.

Manuscript received April 9, 2018; final manuscript received December 3, 2018; published online January 31, 2019. Assoc. Editor: Jonathan Vande Geest.
}

Some techniques make use of the body's own blood pressure variation or blood pressure wave to make estimates about the mechanical properties of the arterial wall. Wall displacement is related to the pulse pressure through the arterial compliance $k_{p}$ as

$$
k_{p}=\frac{d A}{d P}
$$

with $d A$ being the incremental change in cross-sectional vessel area and $d P$ being the corresponding increment of pulse pressure. Local arterial compliance is related to local arterial wall stiffness [11]. However, assuming that the compliance, $k_{p}$, is determined by the mechanical properties and geometry of the vessel wall requires ignoring boundary conditions such as the effect of surrounding tissue, i.e., assuming that the vessel is "floating in space." Also, an additional measurement is required to approximate the pulse pressure variation at the carotid measurement location, which can be error prone [12]. It should be noted that arterial stiffness in this work is discussed as a form of structural stiffness, i.e., it describes the relation between cross-sectional lumen area and lumen pressure of the artery. This should not be confused with the Young's modulus of, e.g., the surrounding tissue, which is a material parameter describing the relation between stress and strain. 
Table 1 Table summarizing patient data

$N$ (gender)

Age (years)

$D \mathrm{CCA}-\mathrm{JV} \pm \mathrm{SD}(\mathrm{mm})$

$D \mathrm{CCA}-\mathrm{TC} \pm \mathrm{SD}(\mathrm{mm})$

$D \mathrm{CCA}-V \pm \mathrm{SD}(\mathrm{mm})$

$D \mathrm{CCA}$ - skin $\pm \mathrm{SD}(\mathrm{mm})$

Diameter JV $\pm \mathrm{SD}(\mathrm{mm})$

Diameter CCA $\pm \mathrm{SD}(\mathrm{mm})$

Note: Standard deviation $(\mathrm{SD})$, distance $(D)$, radius $(R)$, common carotic artery (CCA), jugular vein (JV), tracheal cartilage (TC), and vertebrae $(V)$. All values are reported as average with error margins as defined by their standard deviation.

As an alternative, the compliance can be determined by tracking the velocity of the blood pressure wave propagating through the blood vessels - the pulse wave velocity (PWV). Assuming negligible radial fluid flow and a flat velocity profile, PWV can be used to estimate the compliance and thus arterial wall stiffness through the Bramwell-Hill equation [13] as follows:

$$
\mathrm{PWV}=\sqrt{\frac{A}{k_{p} \rho}}
$$

With $A$ being diastolic cross-sectional vessel area and $\rho$ being the blood density. PWV is proposed as another method detection of local arterial stiffness [14-16] or even plaque detection [17,18], and does not require blood pressure estimates.

Using US, pulse wave imaging (PWI) tracks the propagation of the intrinsic pulse wave across the width of an US transducer using speckle tracking to determine the vessel wall displacements. The local PWV then can be estimated by tracking a feature on the wave profile, which allows the local vessel compliance or modulus to be estimated $[14,17,19]$. Although reflections are reported to cause problems with this method [20], the pulse wave inverse problem method has been demonstrated to account for these problems by fitting a spatially distributed compliance distribution for a computational model of the governing one-dimensional (1D) pulse wave equations to match the measured PWI data as closely as possible [21].

A promising application of US is mapping strain (rate) distributions of the carotid plaque within the US imaging plane by use of deformation estimation algorithms, or strain imaging. The strain is induced by the natural pulsation of the blood circulation [22] and is associated with the underlying stiffness. Strain imaging has been used to differentiate fibrous plaques from atherosclerotic plaques or from plaques with hemorrhage or thrombosis [23], it has been shown to correlate with neovascularization as assessed with contrast-enhanced US [24], with a cognitive performance score [25], and with magnetic resonance imaging (MRI) [26].

For the purpose of strain imaging, PWI and compliance assessment, arterial wall displacement is traditionally being imaged through longitudinal sections of the artery visualizing top and bottom arterial wall only. This is a practical consideration, taking into account factors such as anatomy, US probe geometry, methodology and measurement sensitivity. An important assumption for analysis of these 1D displacement measurements is that the wall is able to distend freely in all directions, ignoring potential effects of the surrounding tissue or stress caused by the actual measurement procedure trough the US measurement probe, as the actual measurement procedure involves pushing the US probe on the flesh, causing substantial secondary stresses and deformations.

However, nearby anatomical structures potentially bias this approach. The anatomy surrounding the CCA is highly variable, and it is bordered by considerably stiffer structures such as the laryngeal cartilage and the vertebrae, as well as softer structures such as the jugular vein and surrounding tissue. It has been suggested from the literature that these structures can have an effect on both the true arterial compliance by restricting the expansion of the artery cross section, and the apparent values estimated from measurements of the top and bottom wall only, which can be affected by out-of-plane motion [27,28].

In this work, we hypothesize that the even radial expansion of the CCA can be biased by the mechanical properties of the surrounding tissue, by its anatomical position relative to both hard (vertebrae and laryngeal cartilage) and soft (skin surface and the jugular vein) structures. Additionally, we hypothesize that stresses caused by the US probe during a typical CCA stiffness measurement can also bias even radial expansion of the CCA. Consequently, we hypothesize that aforementioned parameters can have a measurable effect on the outcome of a stiffness measurement using only 1D displacement data, as compared to a stiffness measurement where the true area change is taken into account.

To test these hypotheses, we conduct a parametrical study on 60 two-dimensional (2D) plane strain finite-element models (FEM) based on anatomical computed tomography (CT) scans of ten healthy volunteers aged between 38 and 60 years old. In these models, we compare the PWV as derived from a simulated 1D compliance assessment $\left(\mathrm{PWV}_{\mathrm{us}}\right)$ with the true PWV $\left(\mathrm{PWV}_{\mathrm{gt}}\right)$ as derived from the entire area change. We compare the results including and without including stresses as induced by the US probe. In an additional experiment, we compare $\mathrm{PWV}_{\mathrm{gt}}$ in the

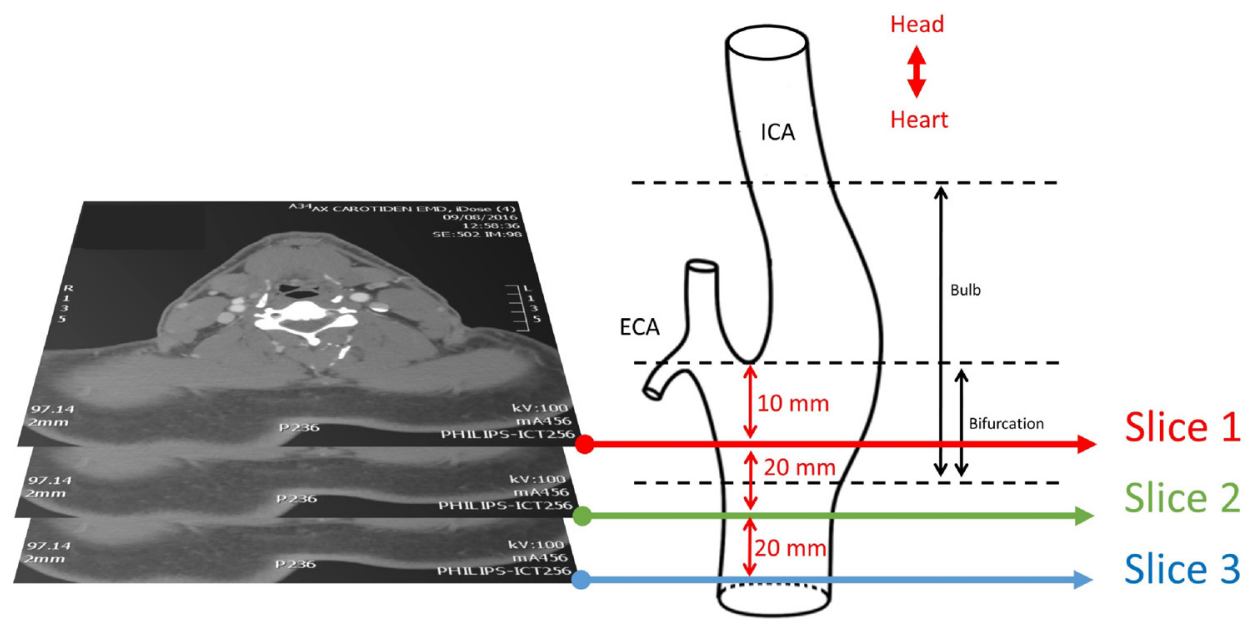

Fig. 1 Schematic rendition of the CCA and the bifurcation. CT slice 1 was always taken $10 \mathrm{~mm}$ below the wall of the far side of the bifurcation. Slice 2 and 3 were taken 20 and $40 \mathrm{~mm}$ below slice 1, respectively (not to scale). Common carotid artery (CCA), internal carotid artery (ICA), external carotid artery (ECA), carotid bifurcation (Bifurcation), and carotid bulb (Bulb). 

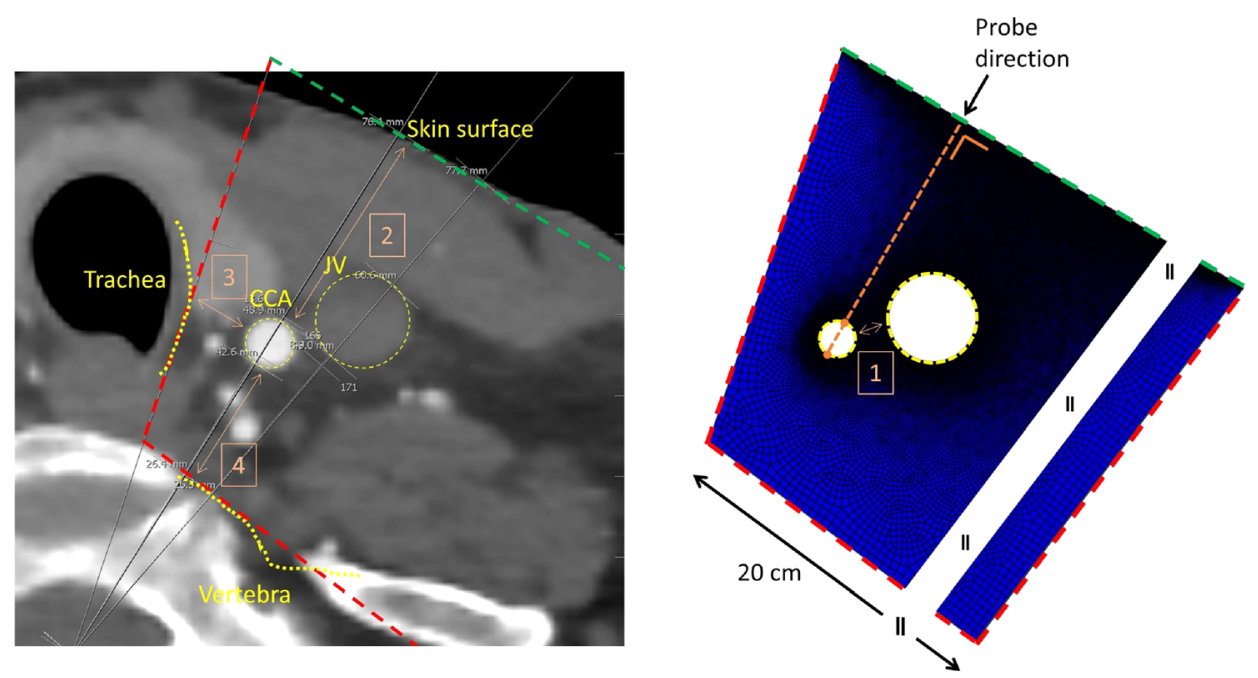

Fig. 2 Example of a CT slice used in this study (left pane), and the simplified parameterized FE model representing potentially important geometrical factors (right pane). The CCA and JV are modeled as circular tubes with a $1 \mathrm{~mm}$ thick isotropic elastic wall $(E=200 / 100 \mathrm{kPa}$, $v=0.49)$ embedded in a softer elastic isotropic medium $(E=1-100 \mathrm{kPa}, v=0.49$, yellow dashed circles), modeled as a nonsliding interface. The elastic isotropic medium has a fixed boundary condition (marked as red dashed lines) where it touches the trachea (yellow dashed line) and the vertebrae (yellow dashed line) as well as $20 \mathrm{~cm}$ away laterally from these structures. In the right pane, parts that are not shown are indicated as (II). The skin surface can move freely (marked as green dashed line). The viewing angle of the probe is considered perpendicular to the skin surface, and going through the center of the CCA (orange dashed line, right pane). Additionally, the mesh is displayed (right pane). Pink numbers/arrows indicate measured parameters: distance between CCA-JV (1), $2.9 \mathrm{~mm}$; distance CCA-skin (2), $28 \mathrm{~mm}$; distance CCA-tracheal cartilage (3), $11 \mathrm{~mm}$; distance CCA-vertebrae (4), $16 \mathrm{~mm}$.
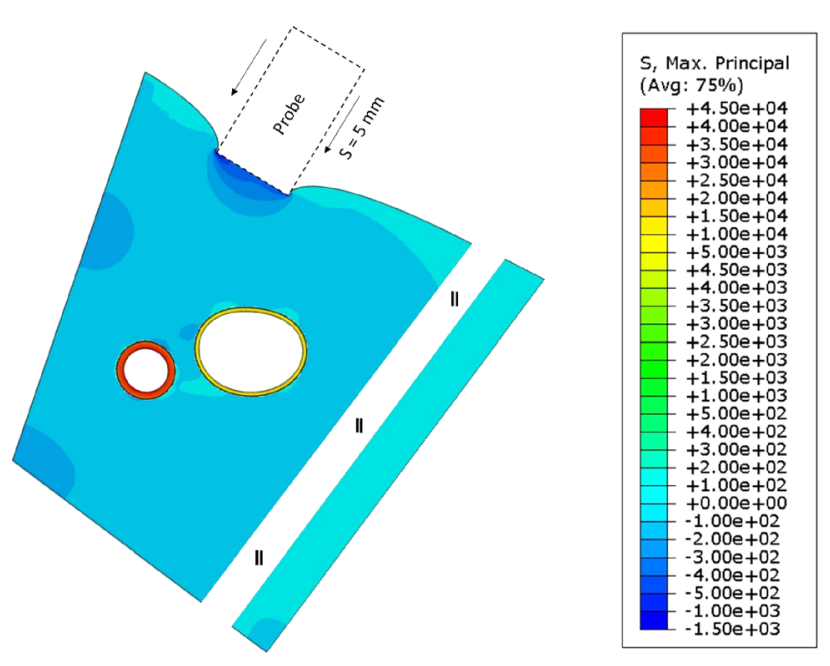

Fig. 3 Deformed FE model, displayed without mesh. The probe movement is modeled as a fixed displacement boundary condition, representing an inward displacement of $5 \mathrm{~mm}$. The circular structures are the common carotid artery (CCA, left) and the jugular vein (JV, right). Maximal principal stresses are displayed, reaching values as high as $45 \mathrm{kPa}$ in this example.

parametrical models, with PWV as predicted in a freely expanding situation $\left(\mathrm{PWV}_{\text {analytic }}\right)$. Finally, we will estimate the bias between the true arterial stiffness and the measured arterial stiffness in an US 1D compliance measurement, and we will investigate the effects of common anatomical features on arterial stiffness.

\section{Materials and Methods}

2.1 CT Images. Ten patients (between 38 and 60 years old) received scans of the cervical region to exclude vascular pathology but were diagnosed as healthy by board certified radiologists.

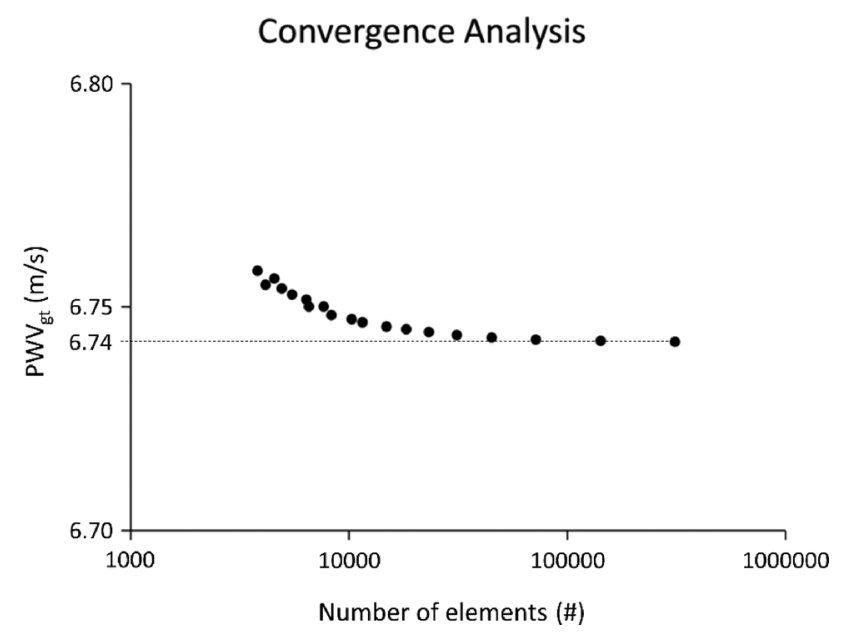

Fig. 4 A convergence analysis was performed. FE models all have between 50,000 and 100,000 elements, depending on their respective size.

Retrospectively, three CT slices of the CCA were analyzed at three locations, both left and right, resulting in a total of six slices representing neck anatomy per patient (60 slices in total) (see Table 1). CT images were made with a Philips ICT 256 slice multidetector $\mathrm{CT}$ in the arterial enhancement phase after intravenous contrast injection according to local diagnostic protocols for evaluation of the carotid arteries.

The analyzed locations were located $10 \mathrm{~mm}$ caudal (i.e., downwards) of the last slice where internal carotid artery (ICA) and external carotid artery (ECA) are not completely bifurcated, and $20 \mathrm{~mm}$ and $40 \mathrm{~mm}$ caudal of the first slice (see Fig. 1). In every slice, the closest distance of the CCA wall to the skin, the closest distance to the nearest bony structures, and the closest distance to 

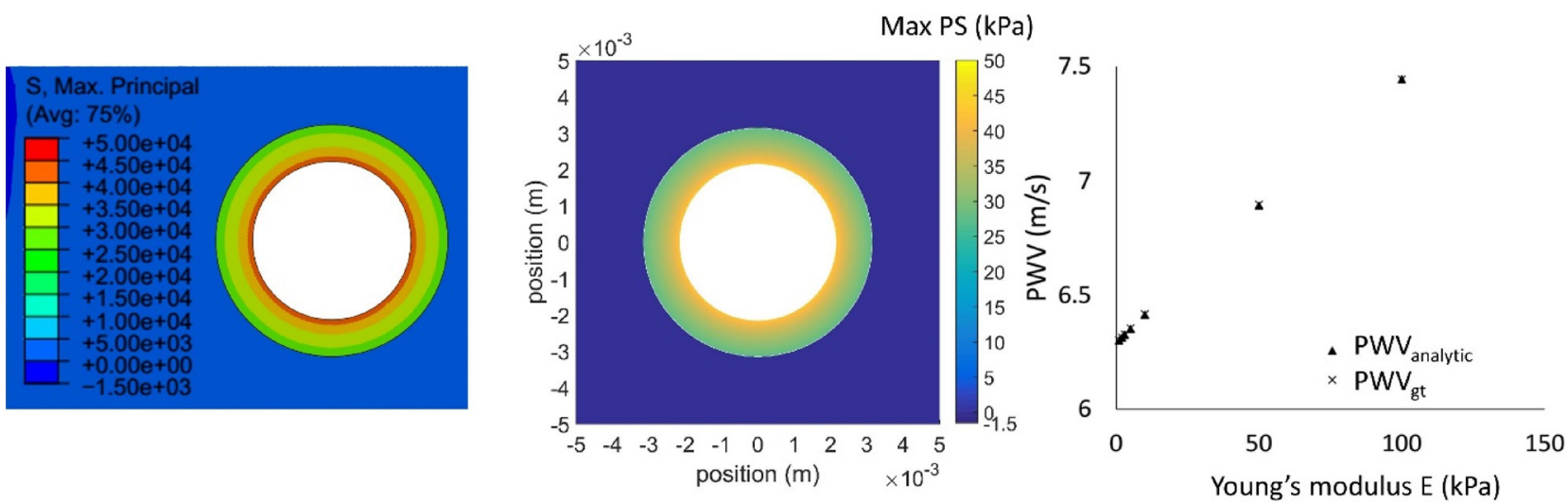

Fig. 5 An analytic model of a thin walled pipe with a fixed Young's modulus $(E=200 \mathrm{kPa}, v=0.49)$ embedded in a softer medium with varying Young's modulus $(E=1-100 \mathrm{kPa}, v=0.49)$ (middle pane) was compared with the FE models of this study (in absence of any probe stresses) (left pane). Results for PWV based analytic and FE models coincide with less than $0.01 \%$ difference (right pane). Max PS = maximal principal stress.

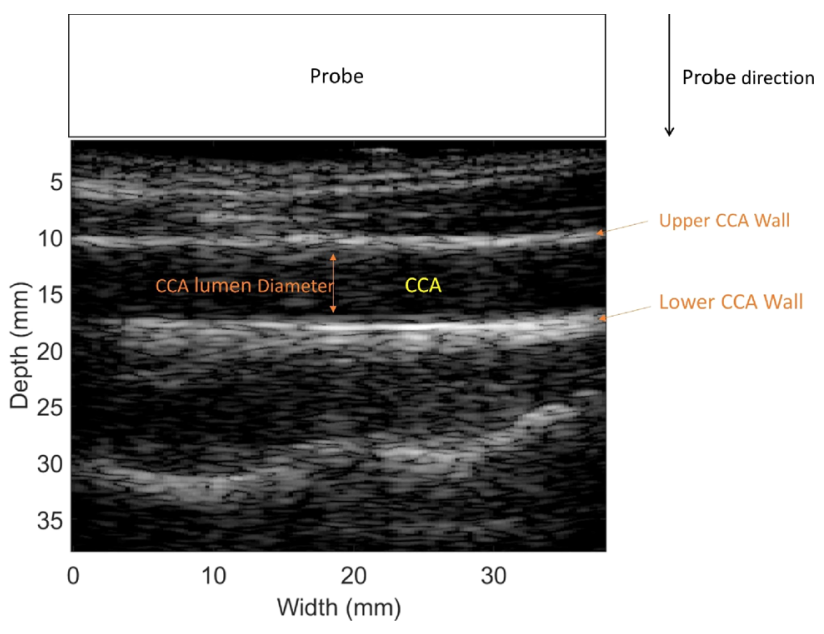

Fig. 6 In order to measure the internal CCA lumen diameter $D$, the probe is placed along the CCA, and the distance between upper and lower CCA wall is measured

the wall of the jugular vein (JV) were determined. These parameters were then used to reconstruct a parameterized finite-element model (FEM, see Sec. 2.2).

2.2 Finite-Element Model. Using the parameters from Sec. 2.1, an idealized FEM was constructed representing the most relevant geometrical features of every slice (see Fig. 2). The important geometrical effects were reduced to a minimum number of parameters to determine the sensitivity of compliance/PWV estimation while minimizing confounding patient-specific effects. Specifically, we examined the distance to the skin surface, distance to the hard surface of the larynx, distance to the jugular vein, presence of stresses induced by the US probe, and Young's modulus of the surrounding tissue, in a range determined by the geometry of the CT images of the ten volunteers. A parametric study was then performed, varying the Young's modulus of the tissue surrounding the vessels. The Young's modulus of the CCA was chosen to be $200 \mathrm{kPa}$ with a wall thickness of $1 \mathrm{~mm}$ [11], and the Young's modulus of the JV was chosen to be $100 \mathrm{kPa}$ with a wall thickness of $0.5 \mathrm{~mm}$ [29], and the Young's modulus of the surrounding tissues was varied between 1 and $100 \mathrm{kPa}$, while the Poisson's ratio of all materials was kept at 0.49 (nearly incompressible) [30-34]. Analyzing software was ABAQUS (ABAQUS version 6.11-1, Dassault Systèmes, Vélizy-Villacoublay, France),
Table 2 Table summarizing patient data

\begin{tabular}{|c|c|c|c|c|}
\hline \multirow[b]{3}{*}{$E \mathrm{ST}(\mathrm{kPa})$} & \multicolumn{4}{|c|}{$\mathrm{PWV} \pm \mathrm{SD}(\mathrm{m} / \mathrm{s})$} \\
\hline & \multicolumn{2}{|c|}{ With probe stresses } & \multicolumn{2}{|c|}{ Without probe stresses } \\
\hline & GT & US & GT & US \\
\hline 1 & $6.09 \pm 0.36$ & $6.01 \pm 0.41$ & $6.10 \pm 0.36$ & $6.09 \pm 0.38$ \\
\hline 2 & $6.10 \pm 0.36$ & $5.97 \pm 0.41$ & $6.12 \pm 0.36$ & $6.10 \pm 0.39$ \\
\hline 3 & $6.11 \pm 0.36$ & $5.94 \pm 0.42$ & $6.13 \pm 0.36$ & $6.11 \pm 0.39$ \\
\hline 5 & $6.12 \pm 0.36$ & $5.90 \pm 0.41$ & $6.16 \pm 0.35$ & $6.13 \pm 0.38$ \\
\hline 10 & $6.16 \pm 0.35$ & $5.88 \pm 0.39$ & $6.23 \pm 0.34$ & $6.20 \pm 0.37$ \\
\hline 50 & $6.47 \pm 0.26$ & $6.10 \pm 0.31$ & $6.76 \pm 0.23$ & $6.73 \pm 0.28$ \\
\hline 100 & $6.84 \pm 0.21$ & $6.44 \pm 0.29$ & $7.34 \pm 0.14$ & $7.32 \pm 0.23$ \\
\hline
\end{tabular}

Note: Young's modulus of surrounding tissue $(E)$, pulse wave velocity (PWV), standard deviation (SD), ground truth measurement (GT), and 1D measurement (US). All PWV values are reported as average with error margins as defined by their standard deviation.

with an average of $1.04 \pm 0.21 \times 10^{5}$ four-node plane strain elements of type CPE4R per model. The analysis was static, as the relatively low frequency of cardiac contractions means that dynamic effects are minimal. Pressure inside the CCA and the JV were raised to $10 \mathrm{kPa}$ and $1 \mathrm{kPa}$, respectively, as a first step, in order to evaluate the diastolic state of the system. In a subsequent step, pressure inside the CCA was raised to $16 \mathrm{kPa}$, for evaluation of the systolic step. Additionally, probe stresses were simulated on the FEM with a displacement boundary condition right above the CCA, simulating $5 \mathrm{~mm}$ indentation in the direction perpendicular to the skin surface, over a region of $10 \mathrm{~mm}$, which corresponds to the level of indentation observed during a typical PWI measurement (see Fig. 3). We assumed measurement US probe direction to be perfectly through the center of the CCA. It has to be noted that in a real-life measurement, this is not always the case as partly reflected in a coefficient of variation of up to $20 \%$ for distensibility measurements [35-37]. However, we did not specifically include the potential effects of the variation in measurement positioning in this study. For verification, a convergence analysis was performed varying mesh density from $5 \%$ to $200 \%$ of the density applied throughout the study (see Fig. 4), and an analytical tunnel-in-gel model of the CCA was constructed (see Fig. 5).

2.3 Analysis. In order to simulate a theoretical distensibility based CCA PWV measurement, PWV was determined by measuring the lumen area and the change in lumen area of the CCA according to Eqs. (1) and (2). dP was assumed to be $6 \mathrm{kPa}$ in all data points, and the $\mathrm{dA}$ is determined as the difference in CCA 
Table 3 Table summarizing statistical analysis

\begin{tabular}{|c|c|c|c|c|c|c|c|}
\hline & $E \mathrm{ST}(\mathrm{kPa})$ & $R$ & $\mathrm{Pp}$ & MWp & $\mathrm{MB}(\mathrm{m} / \mathrm{s})$ & \multicolumn{2}{|c|}{$\operatorname{LOA}(\mathrm{m} / \mathrm{s})$} \\
\hline $\mathrm{PWV}_{\mathrm{gt}}$ versus $\mathrm{PWV}$ us (both with probe stresses) & $\begin{array}{r}1 \\
2 \\
3 \\
5 \\
10 \\
50 \\
100\end{array}$ & $\begin{array}{l}0.99 \\
0.99 \\
0.99 \\
0.98 \\
0.97 \\
0.93 \\
0.89\end{array}$ & $\begin{array}{l}3.0 \times 10^{-59} \\
2.3 \times 10^{-52} \\
6.6 \times 10^{-49} \\
8.2 \times 10^{-44} \\
2.1 \times 10^{-39} \\
2.4 \times 10^{-26} \\
2.8 \times 10^{-21}\end{array}$ & $\begin{array}{l}0.16 \\
0.036 \\
0.010 \\
0.0010 \\
1.6 \times 10^{-5} \\
3.4 \times 10^{-10} \\
3.0 \times 10^{-12}\end{array}$ & $\begin{array}{l}0.085 \\
0.13 \\
0.17 \\
0.22 \\
0.28 \\
0.37 \\
0.40\end{array}$ & $\begin{array}{c}-0.025 \\
-0.0089 \\
0.010 \\
0.039 \\
0.089 \\
0.13 \\
0.13\end{array}$ & $\begin{array}{l}0.19 \\
0.28 \\
0.33 \\
0.40 \\
0.47 \\
0.60 \\
0.67\end{array}$ \\
\hline $\mathrm{PWV}_{\mathrm{gt}}$ versus $\mathrm{PWV}$ us (both without probe stresses) & $\begin{array}{r}1 \\
2 \\
3 \\
5 \\
10 \\
50 \\
100\end{array}$ & $\begin{array}{l}1.0 \\
0.99 \\
0.99 \\
0.99 \\
0.98 \\
0.90 \\
0.73\end{array}$ & $\begin{array}{l}1.4 \times 10^{-67} \\
6.4 \times 10^{-59} \\
2.8 \times 10^{-54} \\
2.2 \times 10^{-48} \\
1.3 \times 10^{-41} \\
9.1 \times 10^{-23} \\
5.4 \times 10^{-11}\end{array}$ & $\begin{array}{l}0.85 \\
0.86 \\
0.76 \\
0.74 \\
0.73 \\
0.88 \\
0.99\end{array}$ & $\begin{array}{l}0.014 \\
0.020 \\
0.024 \\
0.028 \\
0.031 \\
0.031 \\
0.028\end{array}$ & $\begin{array}{l}-0.052 \\
-0.071 \\
-0.083 \\
-0.10 \\
-0.13 \\
-0.21 \\
-0.29\end{array}$ & $\begin{array}{l}0.080 \\
0.11 \\
0.13 \\
0.16 \\
0.19 \\
0.28 \\
0.34\end{array}$ \\
\hline $\mathrm{PWV}_{\mathrm{gt}}$ (without probe stresses) versus $\mathrm{PWV}_{\mathrm{us}}$ (with probe stresses) & $\begin{array}{r}1 \\
2 \\
3 \\
5 \\
10 \\
50 \\
100\end{array}$ & $\begin{array}{l}0.99 \\
0.99 \\
0.98 \\
0.98 \\
0.96 \\
0.79 \\
0.45\end{array}$ & $\begin{array}{l}1.1 \times 10^{-57} \\
7.3 \times 10^{-50} \\
1.1 \times 10^{-45} \\
2.0 \times 10^{-40} \\
1.6 \times 10^{-33} \\
4.1 \times 10^{-14} \\
0.00029\end{array}$ & $\begin{array}{l}0.15 \\
0.019 \\
0.0031 \\
0.00011 \\
9.0 \times 10^{-8} \\
1.3 \times 10^{-17} \\
2.8 \times 10^{-20}\end{array}$ & $\begin{array}{l}0.092 \\
0.15 \\
0.19 \\
0.26 \\
0.35 \\
0.66 \\
0.90\end{array}$ & $\begin{array}{c}-0.024 \\
-0.0064 \\
0.015 \\
0.055 \\
0.12 \\
0.29 \\
0.40\end{array}$ & $\begin{array}{l}0.21 \\
0.31 \\
0.37 \\
0.46 \\
0.59 \\
1.0 \\
1.4\end{array}$ \\
\hline $\mathrm{PWV}_{\mathrm{gt}}$ (without probe stresses) versus $\mathrm{PWV}_{\mathrm{gt}}$ (with probe stresses) & $\begin{array}{r}1 \\
2 \\
3 \\
5 \\
10 \\
50 \\
100\end{array}$ & $\begin{array}{l}1.0 \\
1.0 \\
1.0 \\
1.0 \\
1.0 \\
0.92 \\
0.57\end{array}$ & $\begin{array}{l}3.9 \times 10^{-123} \\
4.4 \times 10^{-104} \\
1.3 \times 10^{-93} \\
1.4 \times 10^{-82} \\
5.4 \times 10^{-65} \\
2.3 \times 10^{-25} \\
2.0 \times 10^{-6}\end{array}$ & $\begin{array}{l}0.68 \\
0.67 \\
0.63 \\
0.45 \\
0.14 \\
7.1 \times 10^{-10} \\
5.4 \times 10^{-19}\end{array}$ & $\begin{array}{l}0.0067 \\
0.015 \\
0.023 \\
0.039 \\
0.075 \\
0.29 \\
0.51\end{array}$ & $\begin{array}{l}-0.00016 \\
0.00070 \\
0.0023 \\
0.0079 \\
0.018 \\
0.091 \\
0.16\end{array}$ & $\begin{array}{l}0.014 \\
0.029 \\
0.044 \\
0.070 \\
0.13 \\
0.49 \\
0.85\end{array}$ \\
\hline $\mathrm{PWV}_{\text {analytic }}$ versus $\mathrm{PWV}$ gt (without probe stresses) & $\begin{array}{r}1 \\
2 \\
3 \\
5 \\
10 \\
50 \\
100\end{array}$ & $\begin{array}{l}1.0 \\
1.0 \\
1.0 \\
1.0 \\
1.0 \\
0.98 \\
0.78\end{array}$ & $\begin{array}{l}4.9 \times 10^{-78} \\
4.9 \times 10^{-78} \\
4.9 \times 10^{-78} \\
4.9 \times 10^{-78} \\
4.9 \times 10^{-78} \\
9.0 \times 10^{-42} \\
2.0 \times 10^{-13}\end{array}$ & $\begin{array}{l}0.68 \\
0.68 \\
0.70 \\
0.68 \\
0.78 \\
0.88 \\
0.32\end{array}$ & $\begin{array}{c}-0.0018 \\
-0.0026 \\
-0.0032 \\
-0.0054 \\
-0.0072 \\
-0.0040 \\
0.019\end{array}$ & $\begin{array}{l}-0.0044 \\
-0.0075 \\
-0.010 \\
-0.015 \\
-0.024 \\
-0.070 \\
-0.11\end{array}$ & $\begin{array}{l}0.00089 \\
0.0023 \\
0.0036 \\
0.0043 \\
0.0096 \\
0.062 \\
0.14\end{array}$ \\
\hline
\end{tabular}

Note: Young's modulus $(E)$, surrounding tissue (ST), Mann-Whitney probability value (MWp), Pearson probability value (Pp), Pearson correlation coefficient $(R)$, mean bias $(\mathrm{MB})$, and limits of agreement (LOA).
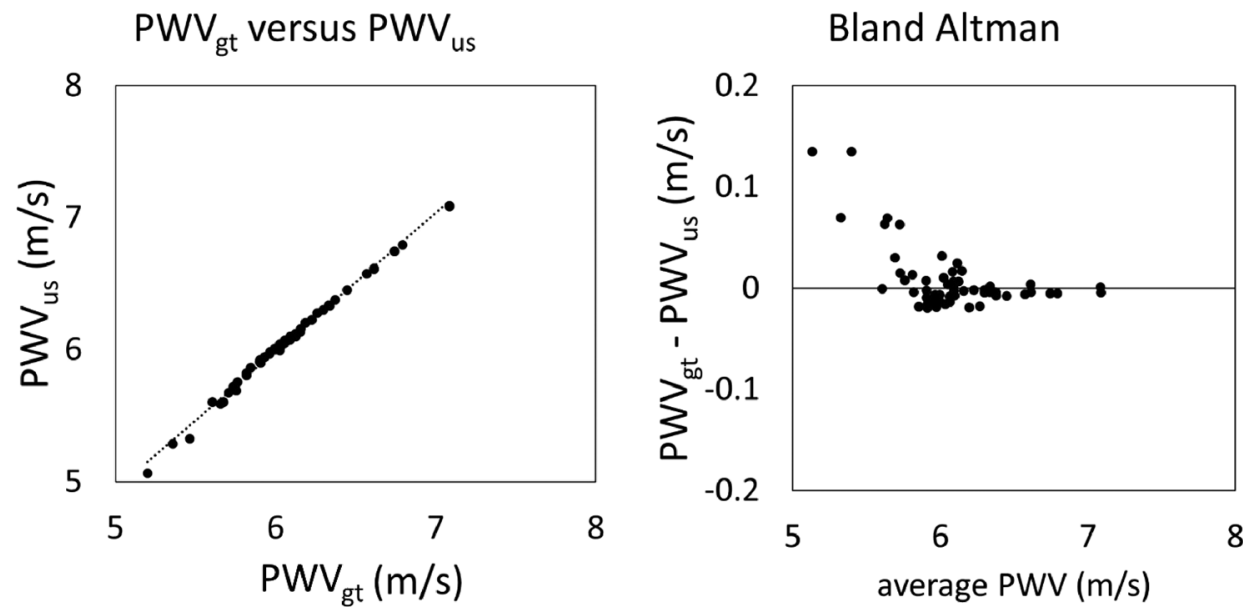

Fig. 7 Correlation plot (left pane) and Bland-Altman plot (right pane) of PWV $\mathrm{V}_{\mathrm{gt}}$ in absence of probe stresses and $\mathrm{PWV}_{\mathrm{us}}$ in presence of probe stresses

lumen area between a prestressed state at $10 \mathrm{kPa}$ and the systolic state at $16 \mathrm{kPa}$.

A lumen area measurement using an imaging probe, or $A_{\mathrm{us}}$, is typically done by tracking the wall displacement of the wall closest, and farthest in the imaging plane, defining the area $A_{\text {us }}$ (systolic or diastolic, see Figs. 2 and 6) as:

$$
A_{\mathrm{us}}=\pi\left(\frac{D}{2}\right)^{2}
$$

With $D$ being the distance between walls in the imaging plane. This area measurement is used to calculate the PWV estimate 


\section{Influence Distance Cartilage}

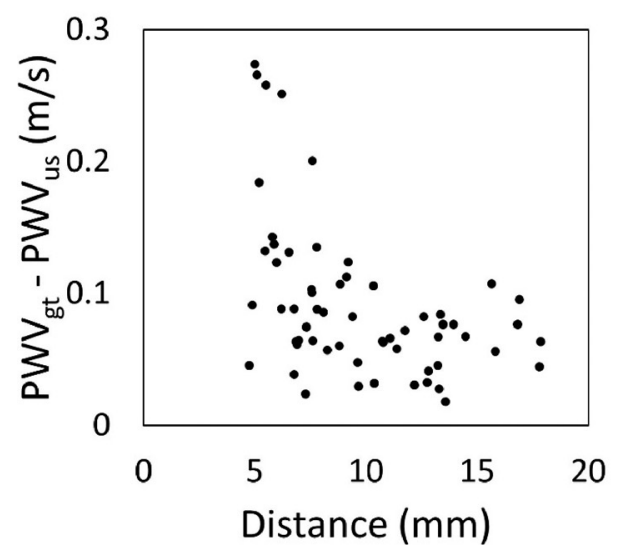

Influence Distance Skin

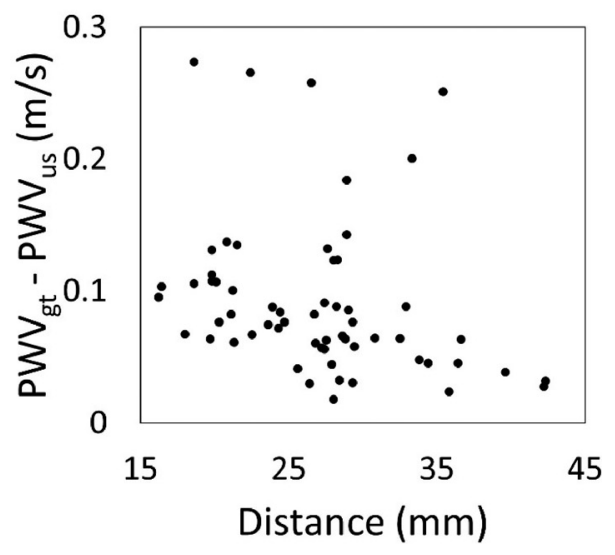

Fig. 8 Correlation plot of the difference between $\mathrm{PWV}_{\mathrm{gt}}$ in absence of probe stresses and $\mathrm{PWV}_{\mathrm{us}}$ in presence of probe stresses as compared to the distance of the carotid to the laryngeal cartilage (left pane) and the skin surface (right pane)

$\mathrm{PWV}_{\mathrm{us}}$. Additionally, a "ground-truth" PWV estimate is made using the lumen area $A_{\mathrm{gt}}$ as calculated from the node coordinates $\mathrm{PWV}_{\mathrm{gt}}$, after arranging the coordinates clockwise and centered around zero (see Fig. 2). If the lumen is delineated by $N$ FEM nodes with coordinates $\left(x_{i}, y_{i}\right)$ (with $\left.i=1: N\right), A_{\mathrm{gt}}$ can be approximated as:

$$
A_{\mathrm{gt}}=\frac{\sum_{i=1}^{i=N} x_{i} *\left(y_{i-1}-y_{i+1}\right)}{2}
$$

$\mathrm{PWV}_{\mathrm{us}}$ and $\mathrm{PWV}_{\mathrm{gt}}$ are compared with and without the deformation caused by the probe. Additionally, $\mathrm{PWV}_{\mathrm{gt}}$ without probe deformation is being compared with $\mathrm{PWV}_{\mathrm{us}}$ with probe deformation. Finally, $\mathrm{PWV}_{\mathrm{gt}}$ without probe deformation was compared with the PWV of the analytical tunnel-in-gel model ( $\left.\mathrm{PWV}_{\text {analytic }}\right)$. Comparison between measurement approach is analyzed with a nonparametric Spearman cross-correlation analysis [38], a Bland-Altman analysis [39,40] and a nonparametric MannWhitney test [41]. Finally, influence of anatomical parameters on the discordance between $\mathrm{PWV}_{\mathrm{us}}$ with probe stresses and $\mathrm{PWV}_{\mathrm{gt}}$ without probe stresses was analyzed with a nonparametric Spearman cross-correlation analysis.

\section{Results}

3.1 Finite-Element Modelling. All PWV values are reported as average with error margins as defined by their standard deviation (SD). At a background Young's modulus of $1 \mathrm{kPa}$, and in the absence of any probe stresses, the average $\mathrm{PWV}_{\mathrm{us}}$ is $6.09 \pm 0.38$ $\mathrm{m} / \mathrm{s}$ and the average $\mathrm{PWV}_{\mathrm{gt}}$ is $6.10 \pm 0.36 \mathrm{~m} / \mathrm{s}$ (see Table 2). $\mathrm{PWV}_{\mathrm{us}}$ and $\mathrm{PWV}_{\mathrm{gt}}$ are not different according to the nonparametric Mann-Whitney U-test, with $p=0.85$, and correlate according to the Pearson correlation analysis, with $R=1.0$ and $p \ll 0.01$. The Bland-Altman analysis with $\mathrm{PWV}_{\mathrm{gt}}$ in absence of probe stresses as the standard shows the limits of agreement are -0.019 and $0.048 \mathrm{~m} / \mathrm{s}$ and that the mean bias is $0.014 \mathrm{~m} / \mathrm{s}$ (see Table 3).

At a background Young's modulus of $1 \mathrm{kPa}$, and in the presence of probe stresses, the average $\mathrm{PWV}_{\mathrm{us}}$ is $6.01 \pm 0.41 \mathrm{~m} / \mathrm{s}$ and the average $\mathrm{PWV}_{\mathrm{gt}}$ is $6.09 \pm 0.36 \mathrm{~m} / \mathrm{s}$ (see Table 2). $\mathrm{PWV}_{\mathrm{us}}$ and $\mathrm{PWV}_{\mathrm{gt}}$ are not different according to the nonparametric Mann-Whitney U-test, with $p=0.16$, and correlate according to the Pearson correlation analysis, with $R=1.0$ and $p \ll 0.01$. The Bland-Altman analysis with $\mathrm{PWV}_{\mathrm{gt}}$ in presence of probe stresses as the standard shows the limits of agreement are -0.052 and $0.080 \mathrm{~m} / \mathrm{s}$ and that the mean bias is $0.085 \mathrm{~m} / \mathrm{s}$ (see Table 3 ).

At a background Young's modulus of $1 \mathrm{kPa}$, comparing $\mathrm{PWV}_{\mathrm{us}}$ in the presence of probe stresses with $\mathrm{PWV}_{\mathrm{gt}}$ in absence of probe stresses, $\mathrm{PWV}_{\mathrm{us}}$ and $\mathrm{PWV}_{\mathrm{gt}}$ are not different according to the nonparametric Mann-Whitney U-test, with $p=0.15$ (see Fig. 7), and correlate according to the Pearson correlation analysis, with $R=0.99$ and $p \ll 0.01$ (see Fig. 7). The Bland-Altman analysis with $\mathrm{PWV}_{\mathrm{gt}}$ in absence of probe stresses as the standard shows the limits of agreement are -0.024 and $0.21 \mathrm{~m} / \mathrm{s}$ and that the mean bias is $0.092 \mathrm{~m} / \mathrm{s}$ (see Table 3).

At a background Young's modulus of $1 \mathrm{kPa}$, comparing $\mathrm{PWV}_{\mathrm{gt}}$ in the presence of probe stresses with $\mathrm{PWV}_{\mathrm{gt}}$ in absence of probe stresses, PWV is not different according to the nonparametric Mann-Whitney U-test, with $p=0.68$ (see Fig. 7), and correlate according to the Pearson correlation analysis, with $R=1.0$ and $p \ll 0.01$ (see Fig. 7). The Bland-Altman analysis with $\mathrm{PWV}_{\mathrm{gt}}$ in absence of probe stresses as the standard shows the limits of agreement are -0.00016 and $0.014 \mathrm{~m} / \mathrm{s}$ and that the mean bias is $0.0067 \mathrm{~m} / \mathrm{s}$ (see Table 3 ).

At a background Young's modulus of $1 \mathrm{kPa}$, comparing $\mathrm{PWV}_{\mathrm{gt}}$ in the absence of any probe stresses with $\mathrm{PWV}_{\text {analytic }}$ without any specific hard or soft tissue effect, $\mathrm{PWV}_{\text {us }}$ and $\mathrm{PWV}_{\text {analytic }}$ are not different according to the nonparametric Mann-Whitney U-test, with $p=0.68$, and correlate according to the Pearson correlation analysis, with $R=1.0$ and $p \ll 0.01$ (see Fig. 5). The Bland-Altman analysis with $\mathrm{PWV}_{\text {analytic }}$ as the standard shows the limits of agreement are $-0.0044 \mathrm{~m} / \mathrm{s}$ and $0.00089 \mathrm{~m} / \mathrm{s}$ and that the mean bias is $-0.0018 \mathrm{~m} / \mathrm{s}$ (see Table 3 ).

At a background Young's modulus of $1 \mathrm{kPa}$, a nonparametric Spearman analysis shows that the difference between $\mathrm{PWV}_{\mathrm{gt}}$ in the absence of any probe stresses and $\mathrm{PWV}_{\mathrm{us}}$ in the presence of probe stresses correlates with the distance to the laryngeal cartilage with $R=-0.48$ and $p \ll 0.01$; and correlates with the distance to the skin with $R=-0.42$ and $p \ll 0.01$, respectively. Other parameters show no significant correlation (see Fig. 8 and Table 4).

At a background Young's modulus of $1 \mathrm{kPa}$, a nonparametric Spearman analysis shows that the difference between $\mathrm{PWV}_{\mathrm{gt}}$ and $\mathrm{PWV}_{\mathrm{us}}$ in the presence of probe stresses correlates with the distance to the laryngeal cartilage with $R=-0.47$ and $p \ll 0.01$; and correlates with the distance to the skin with $R=-0.41$ and $p \ll 0.01$, respectively. Other parameters show no significant correlation (see Fig. 8 and Table 4).

At a background Young's modulus of $1 \mathrm{kPa}$, a nonparametric Spearman analysis shows that the difference between $\mathrm{PWV}_{\mathrm{gt}}$ and $\mathrm{PWV}_{\mathrm{us}}$ in the absence of probe stresses correlates with the distance to the laryngeal cartilage with $R=-0.51$ and $p \ll 0.01$. Other parameters show no significant correlation (see Fig. 8 and Table 4).

At a background Young's modulus of $1 \mathrm{kPa}$, a nonparametric Spearman analysis shows that the difference between $\mathrm{PWV}_{\mathrm{gt}}$ in the absence of any probe stresses and $\mathrm{PWV}_{\mathrm{gt}}$ in the presence of 
Table 4 Table summarizing statistical analysis

\begin{tabular}{|c|c|c|c|c|c|c|c|c|c|}
\hline & \multirow[b]{2}{*}{$E \mathrm{ST}(\mathrm{kPa})$} & \multicolumn{2}{|c|}{ D CCA-JV } & \multicolumn{2}{|c|}{ D CCA-TC } & \multicolumn{2}{|c|}{ D CCA-V } & \multicolumn{2}{|c|}{ D CCA-skin } \\
\hline & & $R$ & $p$ & $R$ & $P$ & $R$ & $p$ & $R$ & $p$ \\
\hline $\mathrm{PWV}_{\mathrm{gt}}-\mathrm{PWV}_{\mathrm{us}}$ (both with probe stresses) & $\begin{array}{l}1 \\
2 \\
3 \\
5 \\
10 \\
50 \\
100\end{array}$ & $\begin{array}{l}-0.060 \\
-0.077 \\
-0.069 \\
-0.085 \\
-0.12 \\
-0.14 \\
-0.097\end{array}$ & $\begin{array}{l}0.65 \\
0.56 \\
0.60 \\
0.52 \\
0.35 \\
0.29 \\
0.46\end{array}$ & $\begin{array}{r}-0.47 \\
-0.47 \\
-0.45 \\
-0.42 \\
-0.33 \\
-0.052 \\
0.031\end{array}$ & $\begin{array}{l}0.00015 \\
0.00016 \\
0.00028 \\
0.00074 \\
0.010 \\
0.69 \\
0.81\end{array}$ & $\begin{array}{c}-0.089 \\
-0.085 \\
-0.071 \\
-0.050 \\
0.033 \\
0.19 \\
0.27\end{array}$ & $\begin{array}{l}0.50 \\
0.52 \\
0.59 \\
0.70 \\
0.80 \\
0.15 \\
0.041\end{array}$ & $\begin{array}{l}-0.41 \\
-0.40 \\
-0.40 \\
-0.42 \\
-0.49 \\
-0.54 \\
-0.52\end{array}$ & $\begin{array}{l}0.0011 \\
0.0015 \\
0.0016 \\
0.00091 \\
7.8 \times 10^{-5} \\
8.4 \times 10^{-6} \\
2.5 \times 10^{-5}\end{array}$ \\
\hline $\mathrm{PWV}_{\mathrm{gt}}-\mathrm{PWV}_{\mathrm{us}}$ (both without probe stresses) & $\begin{array}{l}1 \\
2 \\
3 \\
5 \\
10 \\
50 \\
100\end{array}$ & $\begin{array}{l}0.15 \\
0.17 \\
0.16 \\
0.15 \\
0.13 \\
0.12 \\
0.10\end{array}$ & $\begin{array}{l}0.26 \\
0.20 \\
0.23 \\
0.26 \\
0.31 \\
0.38 \\
0.44\end{array}$ & $\begin{array}{l}-0.51 \\
-0.48 \\
-0.46 \\
-0.42 \\
-0.41 \\
-0.26 \\
-0.19\end{array}$ & $\begin{array}{l}3.6 \times 10^{-5} \\
0.00012 \\
0.00022 \\
0.00075 \\
0.0013 \\
0.041 \\
0.15\end{array}$ & $\begin{array}{r}-0.057 \\
-0.041 \\
-0.039 \\
-0.025 \\
-0.032 \\
0.011 \\
0.038\end{array}$ & $\begin{array}{l}0.66 \\
0.75 \\
0.77 \\
0.85 \\
0.81 \\
0.94 \\
0.77\end{array}$ & $\begin{array}{l}0.27 \\
0.30 \\
0.31 \\
0.35 \\
0.37 \\
0.41 \\
0.40\end{array}$ & $\begin{array}{l}0.040 \\
0.019 \\
0.016 \\
0.0067 \\
0.0041 \\
0.0013 \\
0.0015\end{array}$ \\
\hline $\begin{array}{l}\mathrm{PWV}_{\mathrm{gt}} \text { (without probe stresses) - } \mathrm{PWV}_{\mathrm{us}} \\
\text { (with probe stresses) }\end{array}$ & $\begin{array}{l}1 \\
2 \\
3 \\
5 \\
10 \\
50 \\
100\end{array}$ & $\begin{array}{l}-0.061 \\
-0.077 \\
-0.077 \\
-0.086 \\
-0.14 \\
-0.25 \\
-0.20\end{array}$ & $\begin{array}{l}0.64 \\
0.56 \\
0.56 \\
0.51 \\
0.28 \\
0.056 \\
0.12\end{array}$ & $\begin{array}{l}-0.48 \\
-0.49 \\
-0.48 \\
-0.44 \\
-0.41 \\
-0.28 \\
-0.31\end{array}$ & $\begin{array}{l}0.00012 \\
8.6 \times 10^{-5} \\
0.00011 \\
0.00048 \\
0.0015 \\
0.028 \\
0.014\end{array}$ & $\begin{array}{l}-0.11 \\
-0.10 \\
-0.11 \\
-0.077 \\
-0.074 \\
-0.13 \\
-0.14\end{array}$ & $\begin{array}{l}0.41 \\
0.43 \\
0.42 \\
0.56 \\
0.57 \\
0.32 \\
0.28\end{array}$ & $\begin{array}{l}-0.42 \\
-0.41 \\
-0.43 \\
-0.45 \\
-0.53 \\
-0.67 \\
-0.70\end{array}$ & $\begin{array}{l}0.00096 \\
0.0012 \\
0.00070 \\
0.00031 \\
1.3 \times 10^{-5} \\
6.2 \times 10^{-9} \\
7.1 \times 10^{-10}\end{array}$ \\
\hline $\begin{array}{l}\mathrm{PWV}_{\mathrm{gt}} \text { (without probe stresses) - } \mathrm{PWV}_{\mathrm{gt}} \\
\text { (with probe stresses) }\end{array}$ & $\begin{array}{l}1 \\
2 \\
3 \\
5 \\
10 \\
50 \\
100\end{array}$ & $\begin{array}{l}-0.069 \\
-0.13 \\
-0.17 \\
-0.25 \\
-0.27 \\
-0.21 \\
-0.15\end{array}$ & $\begin{array}{l}0.60 \\
0.34 \\
0.18 \\
0.059 \\
0.038 \\
0.097 \\
0.24\end{array}$ & $\begin{array}{l}-0.34 \\
-0.30 \\
-0.24 \\
-0.16 \\
-0.097 \\
-0.075 \\
-0.11\end{array}$ & $\begin{array}{l}0.0077 \\
0.022 \\
0.068 \\
0.21 \\
0.46 \\
0.57 \\
0.41\end{array}$ & $\begin{array}{l}-0.078 \\
-0.061 \\
-0.042 \\
-0.021 \\
-0.021 \\
-0.099 \\
-0.12\end{array}$ & $\begin{array}{l}0.55 \\
0.64 \\
0.75 \\
0.87 \\
0.87 \\
0.45 \\
0.35\end{array}$ & $\begin{array}{l}-0.54 \\
-0.61 \\
-0.66 \\
-0.72 \\
-0.75 \\
-0.71 \\
-0.68\end{array}$ & $\begin{array}{l}7.2 \times 10^{-6} \\
2.4 \times 10^{-7} \\
7.4 \times 10^{-9} \\
6.7 \times 10^{-11} \\
4.7 \times 10^{-12} \\
2.1 \times 10^{-10} \\
1.9 \times 10^{-9}\end{array}$ \\
\hline $\mathrm{PWV}_{\text {analytic }}-\mathrm{PWV}_{\mathrm{gt}}$ (without probe stresses) & $\begin{array}{l}1 \\
2 \\
3 \\
5 \\
10 \\
50 \\
100\end{array}$ & $\begin{array}{l}\quad 0.11 \\
-0.031 \\
-0.084 \\
-0.12 \\
-0.20 \\
-0.46 \\
-0.56\end{array}$ & $\begin{array}{l}0.40 \\
0.81 \\
0.53 \\
0.37 \\
0.13 \\
2.5 \times 10^{-4} \\
3.7 \times 10^{-7}\end{array}$ & $\begin{array}{l}0.65 \\
0.65 \\
0.66 \\
0.62 \\
0.62 \\
0.50 \\
0.42\end{array}$ & $\begin{array}{l}1.9 \times 10^{-8} \\
1.8 \times 10^{-8} \\
1.1 \times 10^{-8} \\
1.0 \times 10^{-7} \\
1.5 \times 10^{-7} \\
5.6 \times 10^{-5} \\
8.8 \times 10^{-4}\end{array}$ & $\begin{array}{l}0.46 \\
0.43 \\
0.41 \\
0.41 \\
0.38 \\
0.24 \\
0.19\end{array}$ & $\begin{array}{l}2.1 \times 10^{-4} \\
6.9 \times 10^{-4} \\
0.0011 \\
0.0010 \\
0.0024 \\
0.061 \\
0.14\end{array}$ & $\begin{array}{l}0.22 \\
0.22 \\
0.22 \\
0.24 \\
0.24 \\
0.22 \\
0.18\end{array}$ & $\begin{array}{l}0.095 \\
0.098 \\
0.093 \\
0.063 \\
0.060 \\
0.085 \\
0.16\end{array}$ \\
\hline
\end{tabular}

Note: Young's modulus $(E)$, surrounding tissue $(\mathrm{ST})$, distance $(D)$, common carotid artery (CCA), jugular vein (JV), tracheal cartilage (TC), vertebrae $(V)$, Spearman correlation coefficient $(R)$, and Spearman probability value $(p)$. Gray highlights represent statistical significance at $p<0.05$.

probe stresses correlates with the distance to the laryngeal cartilage with $R=-0.34$ and $p<0.01$; and correlates with the distance to the skin with $R=-0.54$ and $p \ll 0.01$, respectively. Other parameters show no significant correlation (see Fig. 8 and Table 4).

At a background Young's modulus of $1 \mathrm{kPa}$, a nonparametric Spearman analysis shows that the difference between $\mathrm{PWV}_{\mathrm{gt}}$ in the absence of any probe stresses and $\mathrm{PWV}_{\text {analytic }}$ correlates with the distance to the laryngeal cartilage with $R=-0.65$ and $p \ll 0.01$; and correlates with the distance to the vertebra with $R=-0.46$ and $p \ll 0.01$, respectively. Other parameters show no significant correlation (see Fig. 8 and Table 4).

The test results for increasing back-ground Young's modulus are summarized in Tables 2-4.

\section{Discussion and Conclusion}

Several studies indicate that arterial stiffness is a function of surrounding tissue and anatomy. The rigidity of the capillary vessel is influenced by the surrounding tissue according to the "tunnel-in-gel" concept as established by Fung et al. [27]. Liu et al. showed that circumferential strain and mean circumferential stress are significantly lower when subjected to radial constraint at physiological pressure in a pig model for carotid and femoral arteries [42]. Asymmetrical expansion of the carotid artery has also been reported in a rat model based on longitudinal sections of the CCA and external carotid artery [43]. Finally, according to Podgórski et al. the JV anatomy potentially biases 1D wall displacement measurements [28]. In this study, we consider the effect of hard and soft anatomical features of the neck region, as well as the effect of the US probe stresses and deformations.

Data considering stiffness of tissue surrounding the CCA are sparse, and tissue stiffness studies are challenging to interpret given the lack of uniformity in stiffness measurement methodology and characterization. Applied deformations in this study are small $[44,45]$, we modeled it as an isotropic linear elastic material and we parametrized the Young's modulus using a range of moduli extracted from the literature. We modeled the neck tissue similar to a bulk of limbs' soft tissue. Bader et al. report a stiffness modulus between 1 and $3 \mathrm{kPa}$ for soft tissue of the forearm and thigh [46], Krouskop et al. report a Young's modulus between 5 and $10 \mathrm{kPa}$ for lower limbs' soft tissue [47], while Zheng et al. report values between 14 and $59 \mathrm{kPa}$ [48], Mak et al. report values between 20 and $140 \mathrm{kPa}$ [49], Reynolds and Lord report values between $50 \mathrm{kPa}$ and $145 \mathrm{kPa}$ [50], Torres-Moreno et al. report values between $27 \mathrm{kPa}$ and $106 \mathrm{kPa}$ [51], and Vannah and Childress report a values between 2 and $600 \mathrm{kPa}$ for lower limbs' soft tissue [52]. These Young's moduli varied among subjects, with sites and with states of the muscular contraction. Based on these and other 
findings from the literature and given that we assume the muscles and tendons are in unstrained state, we limited the range in our model for the Young's modulus between 1 and $100 \mathrm{kPa}$.

Our findings indicate that a 1D CCA stiffness measurement can be affected by stresses caused by application of the ultrasound probe, by the adherence of hard structures such as the tracheal cartilage, and by adherence to the skin surface. The degree of bias as compared to a reference stiffness measurement, is a function of the background Young's modulus.

Comparing the different approximations for PWV in different circumstances, we observe that probe stresses have a more pronounced effect as background stiffness increases. In particular we note that $\mathrm{PWV}_{\mathrm{gt}}$ and $\mathrm{PWV}_{\mathrm{us}}$ correlate when probe stresses are present, but bias between measurement methods increases up to $0.40 \mathrm{~m} / \mathrm{s}$ for the highest background Young's modulus in our study. Also, we note that the stresses induced by the probe have an effect on the PWV estimation, causing a $\mathrm{PWV}_{\mathrm{us}}$ bias of up to $0.90 \mathrm{~m} / \mathrm{s}$ and a $P W V_{\mathrm{gt}}$ bias of up to $0.51 \mathrm{~m} / \mathrm{s}$ as compared with a situation where probe stresses are absent. These effects are due to the increasing constraints on the vessel caused by the probe. Additionally, when comparing ground-truth and tunnel-in-gel simulations, it is apparent from our data that the nearby hard structures increase apparent arterial stiffness, which increases with increasing background Young's modulus.

The nearby structure of the trachea lateral of the viewing axis of the US probe, has a significant effect on 1D measurement of CCA stiffness, as the level of PWV underestimation decreases with increasing distance of the CCA from the trachea. We hypothesize that this is caused by the flattening effect on the cross section of the CCA relative to the viewing axis due to the extra constraint of the nearby hard trachea. The latter effect also causes an apparent stiffening of the artery as compared to the tunnel in gel model.

The nearby skin surface, on the other hand, causes an underestimation of 1D PWV which decreases with increasing distance from the skin, due to the flattening effect of these parameters on the cross section of the CCA relative to the viewing axis, and due extra constraint in the presence of probe stresses. On the contrary, when probe stresses are minimal, a shorter distance to the skin surface causes an underestimation of arterial stiffness with 1D measurement as the reduced constraint of the free skin surface allows the vessel wall to easily move in that direction.

As limitations to this study, it should be noted that we did not reliably approximate real anatomical background stiffness, due to a lack of data in the field. As an alternative, we incorporated a physiological range of background Young's moduli (1-100 kPa) and we treated the surrounding tissue as an isotropic elastic material. Additionally, we did not consider anisotropy of the CCA or surrounding tissues, stresses caused by blood flow, or other confounding effects of arterial curvature, and we assumed the 2D geometry to be in a plane perpendicular to the tangent of the artery. These assumptions are reasonable for the $\sim 4 \mathrm{~cm}$ CCA segment right under the bulbus commonly imaged with PWI, which in general does not display extreme curvature since it lays on the surface along the neck and can be approached as more or less straight. Segments with significant curvature would require a more complex three-dimensional (3D) analysis.

Instead, we used a highly simplified linear elastic, static, isotropic plane strain model with simplified parametrized geometry to analyze confounding effects from patient-specific geometries and measurement methodology. The simplified model allows us to analyze results as a function of a few carefully selected potential parameters which could influence the apparent vessel compliance measured via US. The ranges of the geometrical parameters were taken from CT images of patients to ensure they are relevant to human imaging. It can be hypothesized that all parameters included in this study influence arterial stiffness. Due to the size of the dataset, however, it was not possible to separate the effects of the different parameters statistically. Therefore, it is plausible that the effect of some parameters is masking others.
In conclusion, the effect of the skin becomes increasingly important with increasing background tissue Young's modulus, while the effect of the nearby tracheal cartilage becomes less pronounced, as reflected in the $p$ - and $R$-values (see Table 4). We hypothesize, that the stresses from the probe are more evenly distributed over the entire neck structure, and that the anatomical features have a more pronounced effect, affecting the behavior of the CCA cross section through the cardiac cycle (Table 3), with increasing background Young's modulus. However, the difference between the ground truth measurement and the 1D measurement remains limited (less than $0.4 \mathrm{~m} / \mathrm{s}$ over all considered geometries), and is in the same order of magnitude as the measurement error of the 1D measurements in practice [37], as reflected in the mean bias and the limits of agreement (see Table 3), and the correlation between methods remains close to 1 for a background Young's modulus below $50 \mathrm{kPa}$.

Therefore, from the results in this study, we conclude that it is safe to approximate arterial stiffness using 1D measurements of compliance or pulse wave velocity, regardless of surrounding anatomy and probe stresses and deformations.

\section{Funding Data}

- Fonds Wetenschappelijk Onderzoek (12F2317N).

- National Institutes of Health (NIH 1-R01-HL098830-01 and NIH 1-R01-HL135734-01A1).

\section{Nomenclature}

$A=$ cross-sectional area

$A_{g t}=$ cross-sectional area estimated with 2D displacement data

$A_{\mathrm{us}}=$ cross-sectional area estimated with $1 \mathrm{D}$ displacement data

$\mathrm{CCA}=$ common carotid artery

$\mathrm{CT}=$ computed tomography

$\mathrm{CVD}=$ cardiovascular diseases

$D=$ distance

$E=$ Young's modulus

$\mathrm{ECA}=$ external carotid artery

$\mathrm{FEM}=$ finite element modeling

$\mathrm{GT}=$ ground truth

ICA $=$ internal carotid artery

$\mathrm{JV}=$ jugular vein

LOA $=$ limits of agreement

$M=$ male

$\mathrm{MB}=$ main bias

MRI = magnetic resonance imaging

$\mathrm{MWp}=$ Mann-Whitney probability value

$p=$ Spearman's probability value

$\mathrm{Pp}=$ Pearson's probability value

$\mathrm{PWI}=$ pulse wave imaging

$\mathrm{PWV}_{\text {analytic }}=$ pulse wave velocity calculated with analytic model

$\mathrm{PWV}_{\mathrm{gt}}=$ pulse wave velocity measured with $2 \mathrm{D}$ displacement data

$\mathrm{PWV}_{\mathrm{us}}=$ pulse wave velocity measured with $1 \mathrm{D}$ displacement data

$R=$ Pearson's correlation index

$R=$ radius

$\mathrm{SD}=$ standard deviation

$\mathrm{ST}=$ surrounding tissue

$\mathrm{TC}=$ tracheal cartilage

$\mathrm{US}=$ ultrasound

$V=$ vertebrae

\section{References}

[1] World Health Organisation, "Cardiovascular Diseases (CVDs)," World Health Organization, Geneva, Switzerland, accessed Jan. 14, 2019, http://www.who. int/en/

[2] Kupari, M., Hekali, P., Keto, P., Poutanen, V. P., Tikkanen, M. J., and Standerstkjöld-Nordenstam, C. G., 1994, "Relation of Aortic Stiffness to Factors 
Modifying the Risk of Atherosclerosis in Healthy People," Arterioscler. Thromb. Vasc. Biol., 14(3), pp. 386-394.

[3] van Popele, N. M., Grobbee, D. E., Bots, M. L., Asmar, R., Topouchian, J., Reneman, R. S., Hoeks, A. P., van der Kuip, D. A., Hofman, A., and Witteman, J. C., 2001, "Association Between Arterial Stiffness and Atherosclerosis: The Rotterdam Study," Stroke, 32(2), pp. 454-460.

[4] Duprez, D. A., and Cohn, J. N., 2007, "Arterial Stiffness as a Risk Factor for Coronary Atherosclerosis," Curr. Atheroscler. Rep., 9(2), pp. 139-144.

[5] Mower, W. R., Quiñones, W. J., and Gambhir, S. S., 1997, "Effect of Intraluminal Thrombus on Abdominal Aortic Aneurysm Wall Stress," J. Vasc. Surg., 26(4), pp. 602-608.

[6] Vorp, D. A., and Vande Geest, J. P., 2005, "Biomechanical Determinants of Abdominal Aortic Aneurysm Rupture," Arterioscler. Thromb. Vasc. Biol. 25(8), pp. 1558-1566.

[7] Safar, M. E., and Laurent, P., 2003, "Pulse Pressure and Arterial Stiffness in Rats: Comparison With Humans,” Am. J. Physiol. Heart Circ. Physiol., 285(4), pp. H1363-H1369.

[8] Laurent, S., Katsahian, S., Fassot, C., Tropeano, A.-I., Gautier, I., Laloux, B., and Boutouyrie, P., 2003, "Aortic Stiffness Is an Independent Predictor of Fatal Stroke in Essential Hypertension," Stroke, 34(5), pp. 1203-1206.

[9] Mitchell, G. F., Parise, H., Benjamin, E. J., Larson, M. G., Keyes, M. J., Vita, J. A., Vasan, R. S., and Levy, D., 2004, "Changes in Arterial Stiffness and Wave Reflection With Advancing Age in Healthy Men and Women: The Framingham Heart Study," Hypertension, 43(6), pp. 1239-1245.

[10] Lee, H.-Y., and Oh, B.-H., 2010, "Aging and Arterial Stiffness," Circ. J., 74(11), pp. 2257-2262.

[11] Milnor, W. R., 1982, Hemodynamics, Williams \& Wilkins, Philadelphia, PA.

[12] Van Bortel, L. M., Balkestein, E. J., van der Heijden-Spek, J. J., Vanmolkot, F. H., Staessen, J. A., Kragten, J. A., Vredeveld, J. W., Safar, M. E., Struijker Boudier, H. A., and Hoeks, A. P., 2001, "Non-Invasive Assessment of Local Arterial Pulse Pressure: Comparison of Applanation Tonometry and EchoTracking," J. Hypertens., 19(6), pp. 1037-1044.

[13] Bramwell, J. C., and Hill, A. V., 1922, "The Velocity of the Pulse Wave in Man," Proc. R. Soc. B, 93(652), pp. 298-306.

[14] Vappou, J., Luo, J., and Konofagou, E., 2010, "Response to 'Potentials and Pitfalls of Local PWV Measurements'," Am. J. Hypertens., 23(9), pp. 935-935.

[15] Campo, A., Soons, J., Heuten, H., Ennekens, G., Govaerts, I., Vrints, C., Lava, P., and Dirckx, J., 2014, "Digital Image Correlation for Full-Field Time-Resolved Assessment of Arterial Stiffness,” J. Biomed. Opt., 19(1), p. 016008.

[16] Campo, A., and Dirckx, J., 2011, "Dual-Beam Laser Doppler Vibrometer for Measurement of Pulse Wave Velocity in Elastic Vessels," Proc. SPIE 8011 p. 80118 Y.

[17] Apostolakis, I. Z., Nandlall, S. D., and Konofagou, E. E., 2016, "Piecewise Pulse Wave Imaging (pPWI) for Detection and Monitoring of Focal Vascular Disease in Murine Aortas and Carotids In Vivo," IEEE Trans. Med. Imaging, 35(1), pp. 13-28.

[18] Li, R. X., Apostolakis, I.-Z., Connolly, E. S., and Konofagou, E. E., 2015, "Intra-Plaque Stiffness Mapping in Carotid Stenosis Patients In Vivo Using High-Frame Rate Pulse Wave Imaging," IEEE International Ultrasonics Symposium, Taipei, Taiwan, Oct. 21-24.

[19] Li, R. X., Luo, J., Balaram, S. K., Chaudhry, F. A., Shahmirzadi, D., and Konofagou, E. E., 2013, "Pulse Wave Imaging in Normal, Hypertensive and Aneurysmal Human Aortas In Vivo: A Feasibility Study," Phys. Med. Biol., 58(13), pp. 4549-4562.

[20] Nandlall, S. D., Goldklang, M. P., Kalashian, A., Dangra, N. A., D’Armiento, J. M., and Konofagou, E. E., 2014, "Monitoring and Staging Abdominal Aortic Aneurysm Disease With Pulse Wave Imaging," Ultrasound Med. Biol., 40(10), pp. 2404-2414.

[21] Mcgarry, M., Li, R., Apostolakis, I., Nauleau, P., and Konofagou, E. E., 2016, "An Inverse Approach to Determining Spatially Varying Arterial Compliance Using Ultrasound Imaging," Phys. Med. Biol., 61(15), pp. 5486-5507.

[22] Huang, C., Pan, X., He, Q., Huang, M., Huang, L., Zhao, X., Yuan, C., Bai, J., and Luo, J., 2016, "Ultrasound-Based Carotid Elastography for Detection of Vulnerable Atherosclerotic Plaques Validated by Magnetic Resonance Imaging," Ultrasound Med. Biol., 42(2), pp. 365-377.

[23] Liu, F., Yong, Q., Zhang, Q., Liu, P., and Yang, Y., 2015, "Real-Time Tissue Elastography for the Detection of Vulnerable Carotid Plaques in Patients Undergoing Endarterectomy: A Pilot Study," Ultrasound Med. Biol., 41(3), pp. 705-712.

[24] Zhang, Q., Li, C., Zhou, M., Liao, Y., Huang, C., Shi, J., Wang, Y., and Wang, W., 2015, "Quantification of Carotid Plaque Elasticity and Intraplaque Neovascularization Using Contrast-Enhanced Ultrasound and Image RegistrationBased Elastography," Ultrasonics, 62, pp. 253-262.

[25] Wang, X., Jackson, D. C., Varghese, T., Mitchell, C. C., Hermann, B. P., Kliewer, M. A., Dempsey, R. J., Marler, J. R., Millikan, C. H., Petito, C. K., Price, T. R., Raichle, M. E., Robertson, J. T., Thiele, B., Walker, M. D., Zimmermana, R. A., and Leblanc, G. G., 2014, "Correlation of Cognitive Function
With Ultrasound Strain Indices in Carotid Plaque," Ultrasound Med. Biol. 40(1), pp. 78-89.

[26] Roy Cardinal, M.-H., Heusinkveld, M. H. G., Qin, Z., Lopata, R. G. P., Naim, C., Soulez, G., and Cloutier, G., 2017, "Carotid Artery Plaque Vulnerability Assessment Using Noninvasive Ultrasound Elastography: Validation With MRI,” Am. J. Roentgenol., 209(1), pp. 142-151.

[27] Fung, Y. C., Zweifach, B. W., and Intaglietta, M., 1966, "Elastic Environment of the Capillary Bed," Circ. Res., 19(2), pp. 441-461.

[28] Podgórski, M., Winnicka, M., Polguj, M., Grzelak, P., Łukaszewski, M., and Stefańczyk, L., 2015, "Does the Internal Jugular Vein Affect the Elasticity of the Common Carotid Artery?," Cardiovasc. Ultrasound, 14(1), p. 40.

[29] Nippa, J. H., and Alexander, R. H., 1971, "Pulse Wave Velocity in Human Veins," J. Appl. Physiol., 30(4), pp. 558-563.

[30] Akhtar, R., Sherratt, M. J., Cruickshank, J. K., and Derby, B., 2011, "Characterizing the Elastic Properties of Tissues," Mater. Today, 14(3), pp. 96-105.

[31] Iivarinen, J. T., Korhonen, R. K., Julkunen, P., and Jurvelin, J. S., 2011, "Experimental and Computational Analysis of Soft Tissue Stiffness in Forearm Using a Manual Indentation Device," Med. Eng. Phys., 33(10), pp. 1245-1253.

[32] Van Loocke, M., Lyons, C. G., and Simms, C. K., 2006, "A Validated Model of Passive Muscle in Compression,” J. Biomech., 39(16), pp. 2999-3009.

[33] Zheng, Y. P., and Mak, A. F. T., 1999, "Extraction of Quasi-Linear Viscoelastic Parameters for Lower Limb Soft Tissues From Manual Indentation Experiment," ASME J. Biomech. Eng., 121(3), p. 330.

[34] Huang, Y.-P., Zheng, Y.-P., and Leung, S.-F., 2005, "Quasi-Linear Viscoelastic Properties of Fibrotic Neck Tissues Obtained From Ultrasound Indentation Tests In Vivo," Clin. Biomech., 20(2), pp. 145-154.

[35] van den Berkmortel, F., Wollersheim, H., van Langen, H., and Thien, T., 1998 "Dynamic Vessel Wall Properties and Their Reproducibility in Subjects With Increased Cardiovascular Risk," J. Hum. Hypertens., 12(6), pp. 345-350.

[36] Gamble, G., Zorn, J., Sanders, G., MacMahon, S., and Sharpe, N., 1994 "Estimation of Arterial Stiffness, Compliance, and Distensibility From M-Mode Ultrasound Measurements of the Common Carotid Artery," Stroke, 25(1), pp. 11-16.

[37] McGarry, M., Nauleau, P., Apostolakis, I., and Konofagou, E., 2017, "In Vivo Repeatability of the Pulse Wave Inverse Problem in Human Carotid Arteries," J. Biomech., 64, pp. 136-144.

[38] Spearman, C., 1987, "The Proof and Measurement of Association Between Two Things," Am. J. Psychol., 100(3-4), pp. 441-471.

[39] Bland, J. M., and Altman, D., 1986, "Statistical Methods for Assessing Agreement Between Two Methods of Clinical Measurement," Lancet, 327(8476), pp 307-310.

[40] Altman, D. G., and Bland, J. M., 1983, "Measurement in Medicine: The Analysis of Method Comparison Studies," The Statistician, 32(3), pp. 307-317.

[41] Wilcoxon, F., 1945, "Individual Comparisons by Ranking Methods," Biom. Bull., 1(6), p. 80.

[42] Liu, Y., Dang, C., Garcia, M., Gregersen, H., and Kassab, G. S., 2007, "Surrounding Tissues Affect the Passive Mechanics of the Vessel Wall: Theory and Experiment," Am. J. Physiol. Circ. Physiol., 293(6), pp. H3290-H3300.

[43] Nam, K.-H., Bok, T.-H., Jin, C., and Paeng, D.-G., 2014, "Asymmetric Radial Expansion and Contraction of Rat Carotid Artery Observed Using a HighResolution Ultrasound Imaging System," Ultrasonics, 54(1), pp. 233-240.

[44] Klaesner, J. W., Hastings, M. K., Zou, D., Lewis, C., and Mueller, M. J., 2002 "Plantar Tissue Stiffness in Patients With Diabetes Mellitus and Peripheral Neuropathy," Arch. Phys. Med. Rehabil., 83(12), pp. 1796-1801.

[45] Hayes, W. C., Keer, L. M., Herrmann, G., and Mockros, L. F., 1972, “A Mathematical Analysis for Indentation Tests of Articular Cartilage," J. Biomech. 5(5), pp. 541-551.

[46] Bader, D. L., and Bowker, P., 1983, "Mechanical Characteristics of Skin and Underlying Tissues In Vivo," Biomaterials, 4(4), pp. 305-308.

[47] Krouskop, T. A., Muilenberg, A. L., Doughtery, D. R., and Winningham, D. J., 1987, "Computer-Aided Design of a Prosthetic Socket for an Above-Knee Amputee,” J. Rehabil. Res. Dev., 24(2), pp. 31-38.

[48] Zheng, Y., Mak, A. F., and Lue, B., 1999, "Objective Assessment of Limb Tissue Elasticity: Development of a Manual Indentation Procedure," J. Rehabil. Res. Dev., 36(2), pp. 71-85.

[49] Mak, A. F. T., Liu, G. H. W., and Lee, S. Y., 1994, "Biomechanical Assessmen of Below-Knee Residual Limb Tissue," J. Rehabil. Res. Dev., 31(3), pp. $188-198$

[50] Reynolds, D. P., and Lord, M., 1992, "Interface Load Analysis for ComputerAided Design of Below-Knee Prosthetic Sockets," Med. Biol. Eng. Comput. 30(4), pp. 419-426.

[51] Torres-Moreno, R., Morrison, J. B., Cooper, D., Saunders, C. G., and Foort, J., 1992, "A Computer-Aided Socket Design Procedure for Above-Knee Prostheses," J. Rehabil. Res. Dev., 29(3), pp. 35-44.

[52] Vannah, W. M., and Childress, D. S., 1996, "Indentor Tests and Finite Element Modeling of Bulk Muscular Tissue In Vivo," J. Rehabil. Res. Dev., 33(3), pp. 239-252. 